\title{
Enhancing coverage of financial market activity
}

Mohammed Yaqoob

Formerly of the Office for National Statistics

M. Khalid Khan

Office for National Statistics

\section{Summary}

In July 2009 a special edition of Economic and Labour Market Review presented a series of articles identifying areas for improvement in the coverage of financial statistics under the 'Developing financial statistics for policy' programme. This article focuses on the gaps that exist in current statistical coverage of financial activity, especially as it relates to innovation in the financial sector. It is a precursor to the potential development of appropriate statistical measures that will capture the values of new financial instruments and the behaviour of new institutions. The resulting metrics will improve the depth of understanding of financial markets and provide the foundation for relevant and timely macroprudential indicators that will assist in the prediction of systemic risks to financial institutions.

\section{Background}

The financial crisis highlighted the need to improve the quality and coverage of financial statistics for policy purposes. At the end of 2008 , ONS established a number of related projects to make progress on this agenda. The July 2009 issue of Economic and Labour Market Review ${ }^{1}$ presented an interim progress report and a further update was published in January 2011 (Walker 2011).

One of the projects focused on gaps in the present statistical coverage of the financial sector.

Reliable and timely information on transactions involving the financial sector is essential for a number of reasons. The financial intermediation sector in the UK accounts for around 7 per cent of GDP and is therefore an important source of economic prosperity in its own right. It is also a facilitator of many forms of economic activity by providing access to the means necessary to finance transactions. Its impact on other sectors is important for understanding the behaviour of the economy. 
It is therefore necessary to monitor the financial sector's activity closely to prevent undesirable events that may generate systemic risks. One conclusion to be drawn from recent events is the need to give greater emphasis to systemic prudential oversight as well as to oversight of individual institutions. The Bank of England's discussion paper, The role of macroprudential policy ${ }^{2}$, noted:

'Effective macroprudential policy instruments are an important missing ingredient from the current policymaking toolkit, in the United Kingdom and internationally. Had they existed, the current crisis might plausibly have been less costly for the real economy.'

The financial crisis highlighted shortcomings in current data sources which failed to capture the rapid pace of innovation in financial markets and may have impeded the authorities in acting in a supervisory capacity. A good understanding of these developments is especially important in the UK, which lies at the centre of a web of financial interconnectivity and product innovation. The need is for better macroprudential indicators embodying aggregated data across institutions and across sectors. This is complementary to microprudential data requirements that are centred on the soundness of individual institutions.

ONS, jointly in partnership with key stakeholders such as HM Treasury, the Bank of England and the Financial Services Authority, is seeking to improve statistics in a way that will enhance understanding of the activities of the UK financial sector. Such a partnership is essential in order to obtain information from all of the relevant financial institutions and markets. More specifically, success requires:

- clarity as to the information and statistics, not currently available, that are needed

- formulation of clear and agreed plans as to how these statistical gaps could be filled, and

- availability of the resources needed to implement these plans and deliver the required results

With particular reference to the rapid pace of financial innovation, this article identifies gaps that have emerged in the existing statistical coverage of financial products and institutional structures, outlining their growth and the resulting potential for risk transmission. It discusses the scope for future improvements to supplement macro financial indicators, and to enhance understanding of the impact of the financial sector on the real economy. Finally, the framework is expanded to cover linkages within the financial sector, and between it and the rest of the economy, to understand the behaviour of financial flows over time and between institutions.

\section{Current coverage of the financial sector}

ONS categorises financial sector activity according to the European System of Accounts 1995 (ESA95) framework which provides guidelines for measuring macroeconomic activity within the EU. ESA95 is itself based on the international standard of the System of National Accounts 1993 (SNA93).

Coverage of financial sector activity spans two dimensions. The first relates to production activities and provides details of the distribution and use of income resulting from the 'production' of financial sector outputs. The second covers the accumulation of financial and non-financial assets by each 
sector of the economy. The financial accounts therefore record changes in financial assets and liabilities that result in each sector's net borrowing to, or lending from, other sectors of the economy.

ONS publishes statistics covering the activities of the UK financial sector in three main publications:

- the Blue Book

- UK Economic Accounts

- Financial Statistics

\section{Blue Book and UK Economic Accounts}

These two publications present the activity of the financial sector for the purposes of presenting the National Accounts. Blue Book (BB) figures show annual aggregates consistent with the quarterly coverage of UK Economic Accounts (UKEA).

UKEA covers changes in assets and liability positions of five different types of financial institutions:

- Central bank

- Banks and building societies

- Other financial intermediaries and financial auxiliaries

- Insurance companies and pension funds

Detailed data divide assets and liabilities by maturity period. Maturities of less than one year are categorised as short-term, whilst those in excess of one year are long-term. Assets and liabilities are further reported according to their sub-categories. For banks for example, UKEA and Blue Book report the following sub-categories:

- currency and deposits

- securities other than shares

- loans

- shares and other equity

Some assets and liabilities, such as loans, are further divided into different periods of maturity and details are provided about the counter-party ${ }^{3}$.

Blue Book has similar coverage to UKEA, with minor differences. The financial corporations sector covers four major groups of financial institutions:

- Monetary financial institutions - central bank, banks, and building societies

- Other financial intermediaries - institutions that collect savings and allocate them to investment projects, but have liabilities others than currency and deposits. These include leasing corporations, security and derivative dealers, and venture capital companies

- Insurance companies and pension funds - including corporations involved in financial intermediation as a consequence of the pooling of risk $^{4}$. 
- Financial auxiliaries - involved in activities related to financial intermediation but not themselves intermediaries.

An additional feature is a derivative account, but coverage is limited to reported annual positions.

In both publications, the balance sheet data is unconsolidated - that is transactions of assets and liabilities between sub-sectors of the same sector and between institutional units of the same subsector are eliminated.

Data presented in the Blue Book and UK Economic Accounts publications meet the requirements of the SNA and ESA, but do not offer full understanding of the impact of the financial sector on economic activity and risk transmission. Data coverage is focused on high level aggregates. Information on sub-positions and maturity period and on the destination of loans - to PNFCs, to households and to other financial corporations - is not reported. Furthermore coverage has not kept pace with the rapid pace of innovation in financial products, or with the evolution of complex institutional structures that are intertwined with shadow banking activity.

\section{Financial Statistics}

This monthly publication has two parts. The first shows public and private sector financial and monetary data. Most is monthly in frequency; the rest quarterly. The content is not governed by a rigid framework such as the National Accounts, permitting a greater degree of flexibility in determining the precise coverage.

The data cover income, expenditure and transactions involving monetary financial institutions (Bank of England, banks and building societies), as well as non-bank financial institutions insurance companies (long-term and others), pension funds, non-monetary sector credit companies, investment trust, unit trusts, property unit trusts, turnover in securities by other financial institutions, institutional investment, securities dealers.

Additionally, it reports insolvencies in England and Wales; liquidity of large non-financial corporations; capital, share and bond issuance; commercial paper issuance; and stock exchange transactions. The coverage of assets and liabilities is quite detailed - for instance, data for banks include assets and liabilities in sterling and foreign currencies, sight and time deposits, sale and repurchase agreements, acceptance guaranteed, certificates of deposit (CDs) and other short term papers issued, items in suspense and transition, and net derivatives. And it provides detailed analysis of sources of deposits and allocation of loans to non-financial sectors.

Part two of Financial Statistics follows an ESA format and, like Blue Book and UKEA, has a National Accounts focus. But certain data are available with greater frequency and coverage is therefore more timely.

As part of its move to a new website in August 2011, ONS will cease publication of compendia volumes such as Financial Statistics. However the full range of information will continue to be available through the website. 


\section{Financial sector innovation}

Several factors have motivated the rapid pace of financial innovation over recent decades, including the search for risk transfer, portfolio diversification, yield enhancement, arbitrage and efficiency.

The scale and pace of the resulting financial innovation has outstripped the capacity of the available statistics to explain the impact of trends in financial activities on markets and on the economy. This has impaired the capability of policymakers to identify the transmission of financial risk.

This section considers the need for better information on (a) financial products such as derivatives and securitisation, and (b) institutional activities in established banking institutions and in the shadow banking system - the increasingly important role played by non-bank financial sector institutions as non-depository intermediaries between lenders and borrowers. On the whole, detailed measurement of these new instruments has been incomplete at national and international level in most countries, reflecting the fast-moving and confidential nature of financial transactions.

As a starting point, it is necessary to identify the innovations that are most prevalent and that pose potential systemic risk. The prevalence of specific innovations should be quantifiable through data on levels and changes in transaction volumes. The degree to which contagion is likely can be assessed from information on the monetary value of those transactions. Because of the complex inter-linkages within the financial sector, systematic deterioration of balance sheets during times of contraction, as well as sharp rises in value for a given sector or product, can potentially trigger chain reactions that affect the decisions of households and (non-financial) corporations.

\section{Financial products}

\section{Derivatives}

Derivatives are financial contracts whose value and profitability are derived according to market conditions, linked to underlying assets such as stock, currency and interest rates or commodities (see Box 1 for types of derivatives). The outlay in any single transaction can amplify exposure in terms of risk and reward relative to movements in underlying prices.

Improved coverage of the volume of derivatives transactions would aid identification of the exposure of different sectors to these instruments, as well as the level of counterparty risk and the potential for contagion in the event of a deterioration in balance sheets.

Derivatives are designed to transfer risk and uncertainty away from risk averse investors. To achieve this, they require participants willing to take on and trade that risk. But over time, the market has evolved to the point where risky derivative activity is disproportionate to the hedging needs of the economy that they originally served.

Financial intermediaries are able to match those wishing to hedge market movements and ensure certainty with others who wish to gain market exposure, typically earning fees from originating and trading the instrument. It is not unusual for non-financial companies and households to use the 
financial markets for interest rate and foreign exchange derivatives, as well as to invest surplus funds in the money markets. In many cases, they may be doing so indirectly or in ignorance via a commercial or retail banking intermediary, and therefore exposing themselves to greater risks than they would knowingly take.

Far from being homogenised, derivatives are complex and highly differentiated instruments. It is necessary to distinguish exchange-traded derivatives - highly standardised, fungible contracts from over the counter (OTC) derivatives which have features that can be customised with privately negotiated terms and are therefore difficult to re-sell. OTC derivatives therefore have to be unwound through settlement in cash of their market value.

\section{Figure $1 \quad$ Notional OTC derivatives outstanding}

\$ trillions

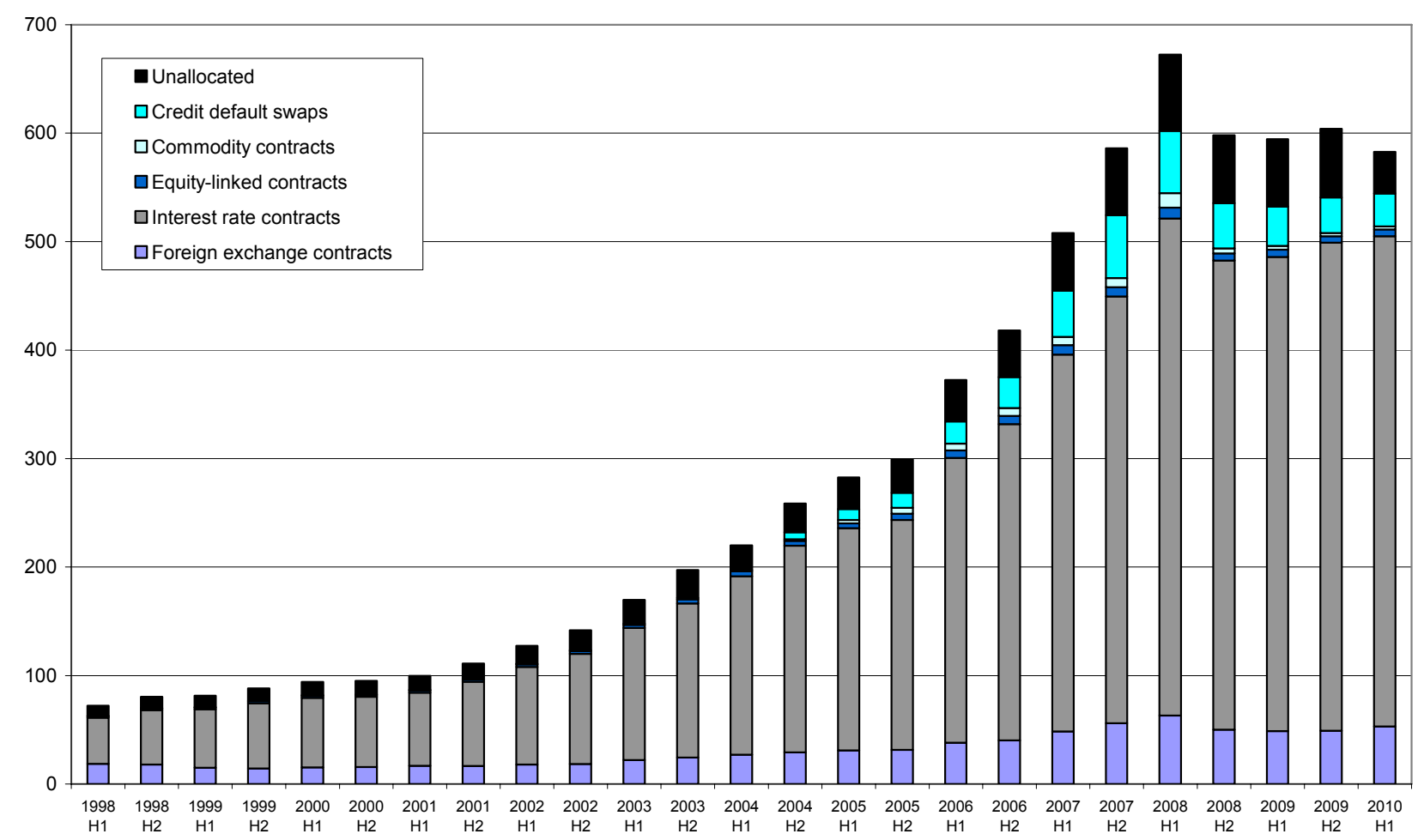

Source: Bank for International Settlements (BIS)

Figure 1 shows the growth of OTC derivatives over the last decade (using global statistics from the Bank for International Settlements (BIS)) which rose from $\$ 72$ trillion in 1998 to more than $\$ 580$ trillion by mid-2010, having peaked at some $\$ 670$ trillion in mid-2008. The rising importance of financial transactions within the economy, combined with the need to engineer bespoke combinations of products, has led to the outstanding value of OTC derivatives reaching a multiple of approximately ten times global GDP. 


\section{Box 1 Types of derivatives}

Interest rate: Concentrating purely on mitigating the risk arising from changes in interest rates, risk averse investors can choose, in their simplest form, futures that lock in certainty through standardised, exchange traded contracts. Bespoke instruments such as forward rate agreements (FRAs) enable the tailoring of contract size as well as maturity and start dates. Others may wish to use swaps to guarantee a fixed stream of income in exchange for a variable rate. Swaps are attractive to those that are risk averse and prepared to forego the benefit of any unexpected favourable outcome. The development of interest rate options enables participants to divest this obligation at a price.

Credit: Credit default swaps (CDS) provide a means of insurance for lenders against the possibility that the borrower should default. The protection seller is a third party who has an obligation to compensate their counterparty in the event of the original borrower defaulting and receives an agreed set of payments in return. Additionally, protection against default can be bought in the form of a basket or index of borrowers. Correlated risk cuts the cost of insuring a basket, relative to the cumulative cost of each component individually.

Foreign exchange: Forwards offer a guaranteed exchange rate at a fixed date in the future for a given amount of currency. Foreign exchange (FX) swaps are two offsetting forward contracts that initiate and unwind at separate future dates. These ensure that currency is provided at the appropriate time. Options free the purchaser from obligations that would prevent their benefiting from unexpected changes in market conditions and can be designed with exotic features. FX derivatives are almost entirely OTC, tailored to the user's needs.

Commodity: Futures and options enable hedging of movements in commodity prices in the manner of a standardised trading exchange. Commodity swaps offer a more bespoke level of certainty and are OTC. Commodity derivatives are available for raw agricultural, energy or processed products. When linked to natural resources, they can be used to offset the risk of movements in production costs, often in conjunction with each other.

Equity: Futures and options linked to stocks or indices in standardised exchange traded contracts were traditionally seen as providing sufficient in the way of portfolio insurance strategies. OTC options enable parties to customise the length and terms of the contract as well as the features to make it exotic. In addition to this, spread combination strategies, offering a linear combination of options at similar or different maturities, can create optimal payoff and risk profiles as well as minimising upfront payments. 


\section{Interest rate derivatives}

Interest rate derivatives are the most popular derivatives by OTC issuance and their versatility makes them the instrument of choice for those wishing to hedge or to speculate on movements in interest rates. With cash as the underlying asset, they offer settlement and valuation with relative ease.

The size of this mature market gives it deep liquidity. Some benchmark interest rates, such as spreads against treasury rates, inflation bonds and overnight indices, can be used to derive indicators of inflation expectations and future interest rates.

\section{Credit derivatives}

The evolution of derivatives from an instrument for risk transfer and hedging to a driver of pure trading activity is most apparent in the evolution of credit derivatives. Credit default swaps (CDS) were designed as an insurance mechanism for transforming risky bonds into investments devoid of default risk. With careful co-ordination, they can be used to diversify risk without totally sacrificing yield. Opportunities exist for hedge funds and proprietary trading desks to write contracts for noninsurance purposes to aid spread arbitrage and yield enhancement strategies. Market growth has produced the benefits of depth of liquidity and greater price transparency.

Its evolution from a means of bond insurance to speculative instrument has resulted in the total aggregate values of CDS contracts worth over five times the notional size of the bond market.

\section{Notional and market values}

Notional amounts outstanding give an indication of the total amount that is at stake in the event of default by the counterparty, and hence the buyers who are at risk from the inability of the counterparty to meet its obligations. They also reflect the effects of a small number of large transactions, which may outweigh large numbers of small transactions.

Changing market conditions affect the market value of derivative contracts. Market value in this context is the exit cost in the event of liquidation. It is possible for a contract to see its market value fluctuate between negative and positive throughout its lifetime. Swap contracts, composed of two offsetting streams of cash flow, were traditionally structured to have a net initiation price of zero, minimising the impact on the balance sheet. Recent changes in the CDS market have led to a process of 'recouponing' to increase fungibility of these contracts so that they are no longer initiated at zero upfront cost.

Market value is therefore a potentially misleading indicator of market growth. But when aggregated across portfolios, institutions and sectors, a sharp decline in market value in a single area may provide an indication of distress and the potential for risk transfer. 


\section{Correlation, volatility and hybrids}

Key themes in identifying risk transmission are volatility and correlation - for instance where the market value of an instrument is linked to the volatility of stocks, currencies, or commodities. In its simplest form, an option to buy or sell an asset for a fixed price in the future makes the value of the option positively dependent on the volatility of the underlying asset. Applied to a basket of assets whose performance depends on inter-related volatility amongst its constituent assets or derivatives, the correlation - if correctly calculated - offers diversification and risk. But it also amplifies the potential loss, and hence the ability to transmit losses to other sectors. The financial crisis has shown how historical patterns of correlation may become unstable during times of uncertainty.

A hybrid structure combines the features of debt, stock and derivatives. This can be in the form of a note whose final value is linked to the performance of an underlying stock, index, commodity, or other assets. The simplest forms of these have already penetrated the retail market in the form of savings products linked to equity market indices with a guaranteed minimum and maximum value. Recently, financial institutions have issued contingent convertible ( $\mathrm{CoCo}$ ) bonds that can convert into stock in the event of distress.

The hybrid nature of such instruments incurs risk exposure to multiple asset classes, and the degree of risk is amplified if it is mis-priced because of failure to capture the impact of volatility or correlation.

\section{Foreign exchange and commodities as investment assets}

Any transaction denominated in a foreign currency is vulnerable to fluctuations in the exchange rate. Similarly production of goods and services that require the purchase of commodities are liable to cost variations. Derivatives can be used to offer insurance against volatile movements in currency and commodity prices.

The foreign exchange and commodity market has developed from a hedging market into a rich source of yield and arbitrage. The OTC nature of foreign exchange forwards and options paves the way for exotic features to facilitate volatility trading, helping achieve an optimal match of hedgers and risk-takers.

Margin trading in various currency and commodity based instruments gives leveraged exposure and is increasing the popularity of these newly investible asset classes. This is most prevalent in the carry trade where borrowing in low interest rate currencies is used to finance re-investment in higher yielding assets in other countries. In the event of this interest rate differential narrowing or reversing, the sale of investment assets and repatriation of funds to unwind the carry trade can amplify capital losses. 


\section{Asset securitisation}

An important channel of innovation has been the securitisation and slicing of debt to prioritise returns and guarantees. Securitisation is the practice of bundling together assets such as debt into bonds, securities or other obligations, which are then sold to investors (Box 2). It has encouraged financial institutions to move away from acting as intermediaries between savers and borrowers towards a business model based on the origination of bulk loans.

\section{Box 2 Asset securitisation}

Mortgage backed securities (MBSs): In their simplest form, repayments of mortgage loans are passed through to buyers of securities. These eventually find themselves categorised into residential mortgage-backed securities (RMBSs) and commercial mortgage backed securities (CMBSs), with the distinction between underlying mortgage loans based on housing and commercial property respectively.

Collateralised mortgage obligations (CMOs): As the nature of mortgages involves risk of prepayment and default, the resulting securities are sliced by order of payment priority. When prepayment and default risk are in line with expectations, risk and reward are aligned with the credit rating. CMOs enable efficient segmentation and risk allocation

Asset backed securities (ABSs): These arise from the extension of securitisation into other cash flow producing assets such as credit cards, car loans and student loans, as well as leasing, intangibles and royalties.

Stripped mortgage backed securities (SMBSs): SMBSs allow separation of the payment streams derived from the principal only (PO) and interest only (IO) components to be channelled to different groups of bond holders.

The resulting securities are essentially bonds that have a market value. Their distribution between financial sector entities at any point may be seen as representative of systemic risks in the event of possible de-leveraging caused by economic contractions. Where these securities are linked to specific real activities, such as residential real estate or vehicle finance, enhanced data may also highlight the potential for distress at a sector level.

A key motivation for innovation in asset securitisation is the capacity to move retail, mortgage or commercial loans off balance sheets and onto conduits. The ability to observe movements in these assets between institutional units provides a picture of credit growth and the degree of financial leverage in household and corporate sectors. 


\section{Collateralised lending}

The inter-bank and wholesale money markets are traditional sources of short term finance. The risk of default, together with rising demand for securities at very short tenors, has created a gap in the market for the facility to lend and borrow cash in exchange for securities. The repo market deals in secured short-term lending through the simultaneous agreement of an immediate sale, and future repurchase, of securities in exchange for cash. Typically in the short-term, the difference in moneys paid at sale and at repurchase represents equivalent interest. In return, the lender of funds has collateral to mitigate for the risk of default.

As the depth of the repo market fulfilled the need for cash, a market emerged for borrowing stocks in return for a cash fee. In essence, securities' lending increases market efficiency through increasing the pool of sellers.

But it raises the prospect that lending of stock could create a vicious circle whereby falling stock prices become self-perpetuating. Whilst it may seem counter-intuitive that holders of assets should assist market participants with an interest in seeing a fall in asset values, the decision to lend is often delegated to managers whose decisions are governed by management fees.

\section{Institutional activities}

Financial institutions have increasingly diversified their activities over the past two decades, culminating in the emergence of large and complex financial institutions (LCFIs) that undertake a range of financial activities.

Activities with exposure to financial markets are described in Box 3. LCFIs may incorporate some or all of these activities. In addition there are many niche players who focus on just one or two functions.

\section{Wholesale markets and loan origination}

As investment banks do not have a depositor base from which to create loans, they operate an originate-and-distribute model for corporate bonds and stocks. This entails syndication with other banks to distribute the securities as financial investments to asset managers and investors. In a liquid market, securities constantly flow from one part of the financial system to another. Information on intra- and inter-institutional flows of securities' origination and trading activity would illustrate emerging risks of over-concentration and imbalance. It would also enable tracking of the credit cycle in the wholesale market for loans, in terms of composition as well as magnitude.

The Turner Review of $2009^{5}$ outlined how the development of securitised credit has led financial intermediaries to move from 'originate-and-distribute' to 'acquire-and-arbitrage' business models. Risk is still held within the system, but lack of transparency prevents identification of the ultimate bearers of that risk. Proprietary trading desks, asset managers, SIVs (structured investment 
vehicles) or subsidiary hedge funds acquire risky securities, financed by the issuance of short-term low-yielding instruments.

\section{Box 3 Large and complex financial institutions activity}

Securities issuance: Raising funds through equity and debt issuance, the capital raising and corporate finance side of an investment bank finances corporations with funds for internal expansion as well as mergers and acquisitions to access funds for capital investment. For shorter term needs, they can use the money markets for working capital.

Wholesale execution: Financial markets match large numbers of buyers and sellers. Aside from distributing securities issued by the corporate finance side of the investment bank, LCFIs can service the transactions needs of large corporations, benefiting from lower costs due to their scale. This is not only for investment of treasury funds but also for financial and risk management.

Prime brokerage: Many hedge funds execute deals with multiple brokers according to their needs. They may find it advantageous to take their financing as well as operational services from a prime brokerage based in a bank or large broker-dealer. In addition to benefiting from their operational, technological and institutional infrastructure, they can benefit from centralised clearing, cross-margining and custody services. Additionally, prime brokers may offer client funds consultancy, capital introduction and marketing services.

Proprietary trading: A recent trend in those large institutions involved in wholesale financial markets has been the dedication of resources to trading for profitability on their own account, in the search for arbitrage opportunities - as opposed to providing transaction services for clients. The asset classes involved in this process are diverse, and typically proprietary desks have been spun off from 'flow' activity, although some banks chose to keep the activities combined.

Asset management: Managers of wealth and assets of funds seek to match assets with future liabilities. Increasingly banking conglomerates have a presence in this area, although there is a degree of separation from investment banking activity. They are usually risk averse, and the use of derivatives is limited by restrictions on the asset classes in which they can invest.

\section{Interconnectivity with shadow banks}

The shadow banking system comprises entities that are independent of, or at arms length from, depository banks and play an increasingly significant role as financial intermediaries (see Box 4). 
Linkages between LCFIs and regulated institutions are common, for example the acquisition by SIVs and by hedge funds of securities issued by banks, the financing of private equity through syndicated loan issuance, or the use of prime brokerage services by hedge funds. Data on LCFIs could therefore indicate the degree of risk embedded within the shadow banking system. However these intermediaries are subject to lighter regulation, and disclosure of information is often voluntary rather than mandatory.

Statistical information must be of sufficient detail to provide insight into the high level of interconnectedness within financial markets. Data on counterparty type and on the distribution between banking and trading book activity, regardless of whether there is an institutional separation, will allow policymakers to observe patterns in proprietary activity, as well as cycles in hedge fund and wealth management, offering a potentially valuable macroprudential perspective.

\section{Box 4 Shadow banking}

\section{Private equity}

Private equity arises where independent single entities are involved in investing in unlisted operating companies. Investors take overall control of target companies through a mixture of equity fund capital and issuance of debt that is eventually added to the company balance sheet. The financing often involves revolving loan facilities with a rate of interest that increases sharply after expiry of an initial period of usually a year. This increases the risk of financial distress and contagion. Other private equity activity includes venture capital and sector focussed investments.

\section{Hedge funds}

Hedge funds are unregulated investment vehicles, usually with an asset or strategy focus. The primary aim - to arbitrage and generate above average returns - works in similar fashion to proprietary trading desks. Seed capital comes from large institutions or high net worth individuals, as well as a significant contribution from managing partners. This capital is subsequently used to gain leveraged exposure to asset classes via the use of derivatives. This multiplication of risk and reward is perpetuated by occasions when offsetting directional positions are taken.

\section{SPVs (special purpose vehicles), conduits, SIVs (structured investment vehicles)}

As deep liquidity eroded spreads between lending and borrowing, there has been an increase in the number of off balance sheet entities of banks, designed to free up capital for originating higher volumes of loans. As shadow banks, they are able to use leverage and maturity transformation to earn profits on the difference between lending and borrowing rates. 


\section{Statistics for highlighting potential risk transmission}

The previous section discussed where to extend and improve the coverage of financial transactions and new financial institutions. This section considers what else is necessary to ensure that the statistical information is collated and presented in a manner which is of greatest benefit in highlighting potential risk transmission.

\section{Greater granularity}

Access to greater detail about the scale and nature of financial activity should give policymakers a clearer picture of the extent to which financial innovation facilitates economic activity, for instance the level of business investment and household spending, as distinct from being designed to maximise returns through pure trading activity with other financial institutions.

There are a number of areas where greater detail could be helpful. For the purpose of identifying risk transmission, it is useful to untangle derivative activity by risk exposure. There have been some moves towards this goal under the 2008 revision of the SNA, separating out forwards, options and employee options. Data on financial instruments should also be decomposed to show underlying sub-categories of exposure. The breakdown of information on new financial products should follow BIS definitions for OTC derivatives - separately identifying interest rate, credit, FX, equity and commodity derivatives.

Measuring the level of asset securitisation warrants a breakdown of securities backed by residential property, commercial property and other assets. In order to observe and disaggregate origination activity from asset value changes, total notional amounts outstanding, transaction volumes and market values of derivatives, asset linked securities and hybrid notes should be published periodically.

In addition, there needs to be a slicing of inter- and intra-institutional activity to observe what is held within different sections of LCFIs and within the shadow banking system if possible. Information on assets and liabilities held by regulated bodies within prime brokerage accounts and proprietary desks, as well as within asset management, would allow the quantification of levels of concentration and systemic risk.

Details of transaction levels of collateralised lending classed by type of collateral, and of transactions across proprietary and banking flow desks, would provide important information on trading book trends. Collection of such data presents challenges. Survey results lack timeliness, and positions may have substantially altered by the time of publication. And institutions may not wish to disclose trading positions for reasons of market sensitivity. However financial technology now has the capability to hold and report positions and this may permit access to anonymised data in a timely manner. 
By observing levels and rates of change of asset origination, redistribution and execution activity, it should be possible to gain a better understanding of cyclical fluctuations in the level of financial activity in different areas. The ability to see the scale of proprietary trading and flow banking activity, along with the extent of balance sheet growth amongst LCFI entities or their conduits, is an element of this. A sufficiently detailed coverage of activity between hedge funds and prime brokerage, with reasonable timeliness, could indicate the possible build up of imbalances. More importantly, there would be greater clarity about where the critical points lie in the event of forced de-leveraging and re-pricing of risk.

\section{Derived indicators}

Aggregated product and institutional category level data can provide a macro picture and is useful in mapping changes in the risks emanating from intra- and inter-sector exposures.

Other diagnostic indicators can be derived from this macro level information to enhance the understanding of financial sector activity. For instance, the ratio of liquid liabilities to liquid assets in each sector is a potential indication of the liquidity profile and thus ability to absorb liquidity stress.

With a breadth of nominal and market values of assets and activity, it would be possible to gauge liquidity and capital adequacy within the sector as a whole through calculated ratios. By using indicators of financial innovation disaggregated by risk exposure and activity in conjunction with already available data on asset and liability levels, there is a better chance of alerting policymakers to the existence of any over concentration or unusual behaviour that might be of potential concern.

National and supranational regulators have been discussing macroprudential policy proposals to address problems of hard wired pro-cyclicality within financial markets. It remains to be seen whether any new policy instruments and targets relating to asset bubble containment will operate through existing monetary policy instruments or through explicit use of such derived macroprudential ratios.

\section{Aggregated regulatory data}

Financial regulators are bound by the Basel accords on banking supervision. Basel $\mathrm{II}^{6}$, established in 2004, has three pillars - minimum capital requirements, the supervisory review process, and market discipline. In 2010, Basel $\mathrm{III}^{7}$ - a new global regulatory standard on bank capital adequacy and liquidity - was agreed which further strengthens bank capital requirements and introduces new regulatory requirements on bank liquidity and bank leverage.

As a result of these requirements, national regulators already collect a considerable amount of information on financial activities covering various important dimensions of the financial performance of individual firms, including information on balance sheets, business model, and risk management. They are summarised by the CAMELS acronym - capital adequacy, asset quality, management competence, earning ability, liquidity, and sensitivity to market risk. 
Recently the framework has been extended to meet enhanced disclosure requirements relating to trading activity and complexity. It is not currently published at an aggregated level in the $\mathrm{UK}^{8}$, and provision of this data on a quarterly basis will further enhance the depth and diversity of information available to regulators. By enabling market observers to assess the health of the financial sector in a more robust way, the open publication of regulatory data, subject to constraints of commercial and market sensitivity, will be another step in the process of improving financial statistics.

\section{Business exposures and concentration}

With extensive inter-linkages between financial institutions, instruments and practices, an individual financial institution may by itself have the ability to withstand an economic shock. But because of problems among its direct and indirect counterparties, it may face a sudden loss of confidence, with the consequence of reduced access to liquidity and wider second order problems. These repercussions are not limited to links with other financial firms but may also apply to links with non-financial firms and households. The recent problems caused by a sharp fall in US house prices for those financial firms exposed to the US sub-prime loans market have been well catalogued.

In the interests of transparency and market monitoring, it is essential that data on these business exposures and concentrations should be available at a level that does not compromise disclosure principles but at the same time allows a sufficient degree of disaggregation to allow observers to map changes and associated movements in risk. These issues can be analysed by means of flow of fund statements, as well as using more detailed network risk analysis.

\section{Flow of funds}

The available statistical information must be collated and presented to good effect if it is to be helpful for the purposes of illuminating the financial behaviour of institutions and sectors, and thereby shifts in the underlying pattern of risk bearing. This requires a framework which ensures the consistent allocation of activities between sectors and over time.

In the US, this has long been achieved by dint of the quarterly flow of funds accounts compiled by the US Federal Reserve and articulated with full sectoral balance sheet information. In the UK, the National Accounts framework goes some way to achieving the same objective. While its coverage of the financial sector is less detailed than the US version, it nevertheless provides a sound framework that imposes an economy-wide consistency on the presentation of financial statistics.

In order to build a macroprudential picture, detailed balance sheet data is required, encompassing innovations in financial products and institutional developments. Financial institutions hold in their position keeping systems the notional (face) value of securities at issuance as well as their market value. These data are not confined to a snapshot of values on their balance sheet but also show flows of transactions as well as historical and qualitative data on counterparties. Considerable resource is allocated by the financial sector to constantly improve the technology and analysis for evaluating this for their internal purposes. In future there may be an expansion in the use of 
central counterparties and third party trade repositories that hold both individual transactional and aggregated data as a result of regulation requirements to improve transparency and operational efficiency.

With better statistical coverage of the scale of asset and liability levels, origination activity and market value changes across financial products and between institutional activities, this framework would enhance understanding of the flows of funds within the financial sector and with other sectors of the economy.

Flow of funds analysis could help to identify concentration of funds in specific products, sectors or types of institution. The information should give policymakers the benefit of increased awareness of sector balance sheet flows and positions, in addition to existing data on output, inflation and profitability measures.

\section{Network risk metrics}

While flow of funds data is an essential step towards proper understanding of macro-prudential risk, it does not by itself tell policymakers where the risks ultimately lie. Highly interconnected financial sector institutions face significant exposure to shocks in other sectors and in the rest of the world, either directly or indirectly. Mapping of these networks of connections is also part of the process for improving financial oversight.

Data from flow-of-funds is generally bilateral in nature, showing flows from one sector to another. Some commentators have gone further by proposing data embodying exposure and network metrics to show product exposure between institutional categories. The analysis of network trails between institutions could be extended to cover exposures across financial instruments and across non-financial sectors. A particular exposure may put financial strain on a single institution which, operating through its network of connections, may begin or exacerbate the process of contagion.

The presentation of such multi-dimensional analysis would require extensive tabular data disclosing the bilateral exposure between institutions. The collation of such data poses steep challenges, requiring legal, political, and administrative issues to be addressed.

Nevertheless the benefits of this extra dimension could be significant. It opens the possibility of providing greater clarity on the potential for network risk transmission. Such metrics could be prepared for the financial sector as a whole, for a specific sub-sector, such as banks, or even for a group of financial firms that are considered pivotal for systemic stability.

\section{Conclusion}

ONS has now launched a new phase of its work programme for developing financial statistics. As well as rectifying some of the gaps identified in this article, it will consider how to improve the quality of the sectoral accounts and sectoral balance sheets in order to provide the authorities with 
the information that they require for the conduct of both macroeconomic and macroprudential policy.

Central to the four-year project will be the new forum of experts from the institutions most directly involved in supplying and using data on financial activities, including the Bank of England, HM Treasury and the FSA, but also other relevant bodies. Among its first tasks will be an assessment of the feasibility and desirability of enhancing the coverage, quality and level of detail of financial statistics, bearing in mind not only the needs of policymakers but also the potential availability of the data sources that will be essential to the assembly of reliable statistics.

\section{Notes}

1. The special edition of the Economic \& Labour Market Review on 'Developing financial statistics for policy' is available at: www.statistics.gov.uk/elmr/07_09/

2. The role of macroprudential policy - a discussion paper, Bank of England, November 2009. Available at: www.bankofengland.co.uk/publications/other/financialstability/roleofmacroprudentialpolicy091121.p df

3. ESA 1995 uses three levels of reporting classification: category, sub-category, and subposition. For more details of classification see Chapter 5 . Available at:http://circa.europa.eu/irc/dsis/nfaccount/info/data/ESA95/en/een00231.htm

4. For a complete detail of corporations under each category, see chapter 2 of the ESA 1995.

5. The Turner Review: A regulatory response to the global banking crisis, March 2009. Available at: www.fsa.gov.uk/pubs/other/turner_review.pdf

6. www.bis.org/publ/bcbsca.htm

7. www.bis.org/bcbs/basel3.htm

8. The IMF's annual Global Financial Stability Reports provide data on regulatory ratios at national economy level. www.imf.org/external/pubs/ft/gfsr/index.htm

\section{Contact}

elmr@ons.gov.uk

\section{Reference}

Walker G (2011) 'Developing financial statistics for policy - Progress report January 2011', Economic \& Labour Market Review, vol. 5, no. 1 pp 46-58. Available at:

www.statistics.gov.uk/cci/article.asp?ID=2627 